\title{
Maternal Exposure to Enalapril Impairs Alveolarization in Neonatal Developing Rat Lung
}

\author{
Diego N. Capelari ${ }^{1,2}$, Susana I. Sánchez ${ }^{2}$, Hugo H. Ortega ${ }^{3}$, \\ Lucia B. Fuentes ${ }^{2}$
}

\begin{abstract}
${ }^{1}$ Instituto Multidisciplinario de Investigaciones Biológicas (IMIBIO-SL) - Consejo Nacional de Investigaciones Científicas y Tecnológicas (CONICET). San Luis, Argentina

${ }^{2}$ Facultad de Química, Bioquímica y Farmacia. Universidad Nacional de San Luis (UNSL). Ejército de los Andes 950. D5700HHW - San Luis, Argentina

${ }^{3}$ Departamento de Ciencias Morfológicas, Facultad de Ciencias Veterinarias, Universidad Nacional del Litoral (UNL). R.P. Kreder 2805. S3080HOF - Esperanza, Santa Fe, Argentina
\end{abstract}

\begin{abstract}
The renin-angiotensin system (RAS) during fetal or neonatal stages has been involved in lung growth and differentiation process. We studied the effects of maternal exposure to enalapril during late gestation (G13-G21) on lungs from their offsprings. Pregnant rats were administered with enalapril $(2,85 \mathrm{mg} / \mathrm{kg} / \mathrm{day})$ and lungs analyzed at postnatal ages, significant difference between P0 and P30. Enalapril-treatment did not modify ACE activity in mothers, but decreased significantly in P0 treated-pups suggesting direct placental drug transference. sACE expression increased with age in both groups. AT1 receptors expression was high and localized in alveolar, bronchiole and endothelium cells. We detected larger but fewer alveoli with decreased septation at earlier postnatal stage in enalapril-treated pups. Quantification of immunopositive nuclei demonstrated that in treated pups the proliferation impairs in newborn lungs and thus progressively increased during two postnatal weeks, at difference with controls animals, where the highest proliferation levels were at P0 and then decreased significantly. In coincidence, high $\alpha$-smooth muscle actin staining at the tips of developing secondary septal structures was observed at P15, evidencing an active elastogenesis. In summary, decreased ACE activity produced histomorphological changes and an impaired cellular proliferation at the saccular stage; however an active proliferation and elastogenesis, at later stages, suggest that the developing lung has the capacity to recover once treatment was stopped. Alterations in RAS function could contribute to the abnormalities in lung development tissue indicating that the system is one intrinsic factor necessary to differentiation and alveolarization process. However, other local factors could be involved in this mechanism.
\end{abstract}

Keywords: Renin-Angiotensin-System, Angiotensin-Converting Enzyme, Cellular Proliferation, Enalapril, Lung Development

\section{Introduction}

Distribution of the renin-angiotensin system (RAS) is developmentally regulated in a tissue-specific manner. Angiotensin II (Ang II), the active peptide of the RAS, can act as a modulator of growth and differentiation in a variety of cells and tissues [1-4]. The actions of Ang II are mediated by two receptor subtypes designated as $\mathrm{AT}_{1}$ and $\mathrm{AT}_{2}$ [5].

Angiotensin-converting enzyme (ACE, E.C. 3.4.15.1), critical component of the RAS, is a $\mathrm{Zn}^{2+}$ metallopeptidase, responsible for proteolytic cleavage of angiotensin I into Ang II [6]. The ACE gene codifies for two splice variants, the somatic isoform (sACE) expressed primarily in endothelial and epithelial cells, and the testicular isoform [7]. In the lung, ACE activity begins from gestational day 18 and increases fourfold prior to birth (21 days gestation) $[8,9]$.

The discovery of ACE inhibitors represents a major advance in treatment of hypertension, being captopril and enalapril, the first inhibitors approved, widely used in hypertension treatment and other cardiovascular pathologies [10]. ACE inhibitor's administration is contraindicated during pregnancy because of mayor fetal malformations [11,12] and increased risks of fetopathy [13-15] due to their ability to pass the fetoplacental barrier [16]. In previous reports oligohydramnios was described, often accompanied by hypoplastic lungs, respiratory failure and death in the neonatal period $[10,14,15]$. 
Rat lung alveolarization begins during late gestation and continues on the first 2-3 postnatal weeks [17] being sensitive to perinatal treatments [18-20]. Alveoli are formed by septation of large saccules that constitute the gas-exchange region of immature lung. Secondary septa form as ridges that grow into distal air spaces, increasing lung surface and gas exchange capacity $[17,21,22]$.

Studies from the ontogeny and blockade of the RAS provide strong evidence about the role of the RAS during development of different organs [1-4,19,20]. A number of knock-out mice have been developed, the major defects reported were blood pressure reduction, renal pathology and reduced fertility, but no data were provided with reference to lung development [23].

Recently, we reported changes on the histomorphological structure, and expression of proliferation and elastogenesis markers in lung tissue, caused by captopril administered during late pregnancy [19]. Nogueira-Silva et al. [24] demonstrated that all RAS components were constitutively expressed in the rat lung during gestation (G15 to G21) and that Ang II had a stimulatory effect on lung branching, mediated by $\mathrm{AT}_{1}$ receptors.

Although ACE is highly expressed in developing lung $[8,9]$, the effect of ACE inhibitors administered during late pregnancy has not been extensively studied on developing lung of offsprings born from pregnant rats treated. A few studies have evaluated the role of the RAS in lung development, and its functional differentiation is not clearly established. Thus, we performed prenatal treatment with clinical enalapril doses administered during the last week of pregnancy, critical for organogenesis, and evaluated the effect on lung development offspring's.

\section{MATERIALS AND METHODS}

Animal Treatment

Pregnant Wistar rats (230-250g) were kept in a darklight cycle $\left(12: 12 \mathrm{~h}\right.$, at $\left.22 \pm 1^{\circ} \mathrm{C}\right)$ and fed with standard rodent food and water ad libitum. On the 13th day of pregnancy (G13), they were randomly assigned to two experimental groups: control $(n=6)$ and enalapril treated $(n=6)$ rats. Mini-osmotic pumps (Alzet model 2001; Palo Alto, CA) were implanted subcutaneously between the scapulae bones under light ether anesthesia [3], containing sterile isotonic saline solution (control), or enalapril maleate $((\mathrm{S})-1-[\mathrm{N}-[1-$ (ethoxycarbonyl)-3-phenylpropyl]-L-alanyl]-Lproline maleate, Sigma, USA) in a dose $2,85 \mathrm{mg} / \mathrm{kg} /$ day. The in vivo effects of prenatal exposure to enalapril were evaluated at different postnatal ages: 0 (P0), 8 (P8), 15 (P15) and 30 (P30) days.
The Local Ethical Committee of the Universidad Nacional de San Luis approved all animal experimentation protocols. Animals were handled in accordance with the Guide for the Care and Use of Laboratory Animals as adopted and promulgated by the National Institutes of Health.

\section{Body and lung weight}

Pups from enalapril or control groups were sacrificed by decapitation at different stages P0, P8, P15 and P30 ( $n=3$ per age from six independent treatments). After that, body and lung weights were registered and lung/body ratios estimated.

\section{Blood collection and analysis}

Blood from pregnant rats was periodically collected from G13 until G19, every two days from the tail in tubes without anticoagulant. From each dam, pups were sacrificed by decapitation and blood obtained at P0, P8, P15 and P30. After blood clot tubes were centrifuged at $1.500 \times \mathrm{g}$ for $10 \mathrm{~min}$, serum removed and stored until assay. Serum ACE measurements were performed by a direct spectrophotometric assay based on the hydrolysis of the synthetic tripeptide substrate

2-furanacryloyl-Lphenylalanylglycylglycine (FAPGG) to furanacryloylphenylalanine (FAP) and glycylglycine. Absorbance $(340 \mathrm{~nm})$ was measured after $3 \mathrm{~min}$ and $30 \mathrm{~min}$ incubation at $37^{\circ} \mathrm{C} . \Delta \mathrm{A} / \mathrm{min}$ determination and Unit $\mathrm{L}^{-1}$ conversion was as described previously [25].

\section{Reverse transcriptase-polymerase chain reaction assay}

From each dam, pups were sacrificed by decapitation at P0, P8, P15 and P30 and lungs were harvested, weighed and immediately snap frozen on isopentane $\left(-30^{\circ} \mathrm{C}\right)$ and stored at $-80^{\circ} \mathrm{C}$ until use. Total RNA was isolated using TRIzol reagent (Invitrogen Life Technologies) according to the manufacturer's protocols. RNA's quality was tested by measuring optical density ratios (OD260/OD280) of at least 1.8 and their integrity visualized with agarose gels.

Total RNA $(2 \mu \mathrm{g})$ from lung was retro-transcribed by using M-MLV reverse transcriptase with $1 \mu \mathrm{M}$ oligo$\mathrm{d}(\mathrm{T})$ primer. PCR assays were performed in $20 \mu \mathrm{l}$ final volume, containing cDNA $(2 \mu \mathrm{l}), 2 \mathrm{U}$ of $\mathrm{Taq}$ DNA polymerase [26] using a thermocycler (ep gradient Eppendorf mastercycler).

sACE and $\mathrm{AT}_{1}$ receptor primers (Table 1) were designed as described (19). Glyceraldehyde 3phosphate dehydrogenase (GAPDH) mRNA was used as a housekeeping-gene control [27]. PCR products were analyzed by electrophoresis on $1.5 \%$ agarose gels, visualized by GelRed staining and bands quantified using Scion Image. The absence of 
genomic DNA contamination was confirmed by performing PCR with an equivalent amount of total RNA without reverse transcriptase.

\section{Western blotting}

Protein extraction was performed as described [28]. Briefly, lung tissue (300-500 mg) was homogenized (300-500 $\mathrm{mg}$ of tissue) in cold RIPA buffer $(10 \mathrm{mM}$ Tris-HCl, pH 7.4, $150 \mathrm{mM} \mathrm{NaCl}, 1 \%$ Triton X-100, $0.1 \%$ SDS, $1 \mathrm{mM}$ EDTA), containing fresh protease inhibitor (2 mM PMSF). Samples were centrifuged at $10000 \times \mathrm{g}$ for $15 \mathrm{~min}$ and the supernatant was collected and used as protein extract for immunoblotting analysis. Protein concentration was determined by Bradford method, using an absorbance reader (BioTec), and compared to a BSA standard curve.

Proteins $(50 \mu \mathrm{g})$ were subjected to SDS-PAGE, and electroblotted onto nitrocellulose membrane (Millipore-P). Membranes were blocked with 3\% low fat dry milk in tris-buffered saline and $0.1 \%$ Tween 20 (TBS-T). Membranes were then incubated overnight at $4{ }^{\circ} \mathrm{C}$ with anti- $\mathrm{AT}_{1}$ receptor primary antibody (SC-579, 1:2000) and then incubated with secondary antibody $(1: 10.000)$ coupled to HRP (Jackson ImmunoResearch). Blots were developed with ECL and membranes were reprobed for $\beta$ tubulin as loading control.

\section{Lung processing and histological analysis}

For histological analysis only male pups were considered [29]. Briefly, after sacrifice by cervical dislocation, the trachea was exposed and cannulated. Lungs were inflated by applying a constant pressure $(25 \mathrm{~cm}$ of water) with $0.5 \%$ low melting-point agarose dissolved in $10 \%$ buffered formalin ( $\mathrm{pH} 7.4)$ and then incubated on ice to allow agarose to solidify. Left lungs were fixed in $10 \%$ buffered formalin (4 ${ }^{\circ} \mathrm{C}$, overnight) and washed in phosphate-buffered saline (PBS). Fixed tissues were dehydrated in ascending series of ethanol, cleared in xylene and stained with haematoxylin-eosin (H\&E). As lung maturation varies along different regions of the lungs, all studies were performed on the distal portion of the left lobe.

\section{Measurement of mean linear intercept}

The degree of alveolar septation in male pups was estimated by mean linear intercept (MLI) measurements, as described previously [18]. Briefly, eight random lung sections per animal were viewed at $40 \times$ magnifications and a superimposed predetermined grid of known length $(1 \mathrm{~mm})$. The line that crossed a large vessel or bronchus was excluded from evaluation. Points at which an alveolar septum intercepted a line were counted separately. The total length of all lines counted was divided by the total number of intercepts per field examined. MLI, which is inversely proportional to alveolar surface area, was expressed in micrometers $(\mu \mathrm{m})$. Images were acquired using a microscope (Nikon Eclipse 50i).

\section{Immunostaning}

Immunohistochemistry for PCNA and $\alpha$-SMA was performed as described [30]. Sections $(5 \mu \mathrm{m})$ from fixed tissues were mounted on slides treated with 3aminopropyltriethoxysilane (Sigma-Aldrich, St. Louis, MO, USA). After deparaffinization, sections were pre-treated for antigen retrieval with $0.01 \mathrm{M}$ citrate buffer ( $\mathrm{pH}$ 6.0) and microwave. Endogen peroxidase activity was inhibited with $1 \% \mathrm{H}_{2} \mathrm{O}_{2}$ and nonspecific binding blocked with $10 \%(\mathrm{v} / \mathrm{v})$ normal goat serum. Lung sections were incubated with a mouse monoclonal antibody to PCNA (1:200; Santa Cruz Biotechnology, SC-56) or mouse monoclonal antibody to $\alpha$-SMA (1:50; Novocastra-NCL-SMA) for $18 \mathrm{~h}$ at $4^{\circ} \mathrm{C}$ and then with anti-mouse biotinylated secondary antibody (30 min, room temperature). Antigens were visualized by streptavidin-peroxidase (BioGenex, San Ramon, CA) and 3.3diaminobenzidine chromogen (Liquid DAB-Plus Substrate Kit-Zymed, San Francisco, CA) was used. The slides were counterstained with haematoxylin. A minimum of 1000 alveolar cells per sample were counted, and PCNA immunopositive cells were expressed as a percentage. The number of $\alpha$-SMA stained myofibroblasts at the tips of developing septa was counted in 10 fields per lung and 3 lungs per age and treatments were analyzed at $400 \times$ magnification. Sections at P15 from distal portion of the left lung were analyzed in control and enalapril-treated animals.

For co-localization, lung sections were first incubated with mouse monoclonal antibody to PCNA for $1 \mathrm{~h}$ at $25{ }^{\circ} \mathrm{C}$, followed with anti-mouse biotinylated secondary antibody $\left(30 \mathrm{~min}, 25^{\circ} \mathrm{C}\right)$ and visualized by streptavidin-peroxidase (brown). After that, sections were stained with anti-cytokeratin (Zimed) mouse monoclonal antibody (1:500), incubated at $4{ }^{\circ} \mathrm{C}$ overnight and then with anti-mouse biotinylated secondary antibody $\left(30 \mathrm{~min}, 25^{\circ} \mathrm{C}\right)$. Antigens were visualized with amino ethyl carbazol (red) (AEC, Biogenex HK 330-9K).

For $\mathrm{AT}_{1}$ immunofluorescence labeling, lung sections $(12 \mu \mathrm{m})$ obtained in a cryostat at $-30^{\circ} \mathrm{C}$ (Zeiss) were mounted on glass slides (HiFix, $\mathrm{NH}$ ). Sections were fixed with cold acetone (10 min), air dried and rinsed in PBS. Following blockade (Triton X-100, 0.5\% BSA in PBS, $45 \mathrm{~min}$ ), sections were incubated overnight at $4{ }^{\circ} \mathrm{C}$ with rabbit anti- $\mathrm{AT}_{1}$ receptor polyclonal antibody (1:100, SC-579). Slides were rinsed with PBS and incubated with fluorescein isothiocyanate (FITC)-conjugated antirabbit IgG 
(1:200, Santa Cruz Biotechnology) at room temperature, $2 \mathrm{~h}$. Images were acquired with an epifluorescence microscope (Nikon Eclipse 50i).

\section{Statistical Analysis}

Data are expressed as mean \pm SEM. Statistical analysis was done using the Student's t-test for two groups. Statistical differences among groups were compared with the One-way and Two-way Analysis of Variance (ANOVA) followed by Tukey-Kramer's Multiple Comparisons Test and Bonferroni post-test respectively (GraphPad Prism 5). Statistical significance was accepted with probability value of $P<0.05$.

\section{RESULTS}

\section{Body and lung weights}

Pregnant rats were treated during the last week of pregnancy with either, the ACE inhibitor enalapril $(n=6)$ or saline solution as control $(n=6)$. Litter sizes remain unmodified in both control and treated groups (12-14 pups). From each mother, pups of each studied age were weighted, their lungs immediately removed and weighted (Table 2). We found no statistically significant differences between treated animals and the control group for each age when compared either pulmonary or body weight. We also found that sex does no influence body and lung weight at the stages evaluated. Consequently, lung/body weight ratios were not different between enalapril-treated and control group.

\section{Biochemical and molecular analyses of the renin- angiotensin system}

ACE activity was determined in serum from pregnant rats and offspring at different postnatal stages. No significant differences in serum ACE activity in pregnant rats were observed during late gestation with respect to the control (data not shown). However, ACE activity in treated offprints decreased significantly in P0 animals with respect to control $(P<0.01$; Figure 1$)$. No differences were observed from P8 to P30.

sACE expression in lungs, evaluated by RT-PCR, evidenced a significant increase with age (P0 vs P30) in control animals as well as in enalapril-treated ones $(P<0.05$; Figure.2).

The effect of ACE inhibition on Ang II $\mathrm{AT}_{1}$ receptor expression level was evaluated by RT-PCR at different postnatal ages and compared with that of the ubiquous gene GAPDH. The expression remains high during development and no differences were observed between control and treated animals (Figure $3 \mathrm{~A}, \mathrm{~B})$. Protein levels of Ang II $\mathrm{AT}_{1}$ receptor were determined by Western blot. The level of $\mathrm{AT}_{1}$ receptor is higher in $\mathrm{P} 0$ pups and drops after that
(Figure 3C,D). However, no differences were observed in both control and treated groups. A band of the expected MW was observed, confirming the quality of the antibody used. In addition, $\mathrm{AT}_{1}$ receptors localization was evaluated by immunofluorescence assays. $\mathrm{AT}_{1}$ receptor localized at alveolar, endothelial and bronchial epithelial cells (Figure 3E).

On the other hand, $\mathrm{AT}_{2}$ receptor expression was not detectable by RT-PCR in control and enalapril treated animals at the different ages studied (data not shown).

\section{Histological analysis}

Following treatment during pregnancy with enalapril, lung development was evaluated by histological analysis of distal parenchyma sections from control and treated animals at the different studied ages. To exclude the possibility of variation due to sex [29], just male pups were considered for histological evaluation. Figure 4A shows the typical architecture in control lungs at P0, P8, P15 and P30 (a, c, e and g, respectively). Lung histology in enalapril-treated group revealed striking differences in the histoarchitecture of $\mathrm{P} 0$ rats, with impaired alveolar formation, resulting in enlargement of distal airway spaces (Figure 4A). Lungs from P8, P15 and P30 from the enalapril-treated group showed no differences with the control ones. Lung architecture was evaluated by MLI quantification in enalapril and control groups. MLI was significantly increased in enalapril-treated P0 animals, suggesting an increased interalveolar wall distance in neonatal pups born from treated mothers $(\mathrm{P}<0.01$; Figure $4 \mathrm{~B})$.

\section{Immunohistochemistry of PCNA and $\alpha$-SMA}

In order to compare cell proliferation in control and treated animals, we performed immunohistochemistry staining for PCNA, a marker of cellular proliferation, in the distal parenchyma at the different stages. The PCNA-positive cells in developing alveoli occur in pneumocyte nuclei localized predominantly along the air-tissue interface (Figure 5A). In control animals cell proliferation decreased significantly with age (Figure 5A a,c,e) and in treated group increased from P0 to P15 (Figure $5 \mathrm{~A} \mathrm{~b}, \mathrm{~d}, \mathrm{f})$. Quantification of PCNA marker in enalapril-treated lungs showed a significantly lower value at $\mathrm{P} 0(\mathrm{P}<0.001$; Figure $5 \mathrm{~B})$ and then increased, reaching a maximum level at $\mathrm{P} 15(\mathrm{P}<0.05)$. Double immunolabeling with PCNA and cytokeratin allowed us to differentiate nucleus expressing PCNA (brown) as pneumocyte cells in alveolar septae from pulmonary alveolar epithelium expressing cytokeratin (red) at P15 (Fig. 5C). 
Since the higher proliferation was observed in P15, lungs from enalapril-treated animals were evaluated for $\alpha$-SMA localization by immunohistochemistry, a marker of interstitial myofibroblasts during septal formation [31]. In control and treated lungs (Figure 6 $a, b)$, a strong and specific $\alpha$-SMA immunostaining was observed in smooth muscle cells of bronchial, bronchiolar and vessel walls. At higher magnification (Figure $6 \mathrm{c}, \mathrm{d}$ ), $\alpha$-SMA immunostaining in lungs from P15 enalapril-treated animals was prevalent at the tips of the developing secondary septa. However, in the control group, this marker was prevalent in smooth muscle of bronchiolar and vessel walls, but was not present in developing septae at P15 (Figure $6 \mathrm{a}, \mathrm{c})$. The number of developing tips per field was higher at P15 in those animals born from mothers treated with enalapril than in control animals $(4.05 \pm 0.25$ vs. $2.8 \pm 0.20, \mathrm{p}<0.05)$.

\section{Discussion}

The ontogeny of RAS expression in early fetal or neonatal stages has evidenced that the different components of the RAS are spatial and temporally regulated [1]. The fetal intrapulmonary RAS has been described, suggesting a potential participation of the RAS in the physiological processes of pulmonary development [9, 24, 32]. ACE inhibitors can be teratogenic in human embryos [11-15], while in animals, RAS inhibition causes fetopathies and renal anomalies after birth [3,4,10]. However, detailed evaluation of lung malformation in either knock-out mice or animals treated with ACE inhibitors remains unexplored. Recently, we showed histomorphological and proliferative alteration in lungs from animals treated with captopril during late gestation (19). The present study demonstrates histomorphological alterations and a modified expression of PCNA and $\alpha$-SMA markers in lungs from pups born from mothers treated with enalapril during late pregnancy (G13-G21).

We designed an experimental model of treatment of the pregnant rat in order to avoid drastic teratogenic effects, allowing us to evaluate the participation of the RAS in development. Thus, we choose a dose which did not lower the blood pressure of the mother or causes changes in pup's weight. The period of drug administration (G13 to G21) is coincident with the organogenesis in the rat, and thus was selected to study the potential role of ACE during lung development. In rodents, lung alveolarization begins during late gestation and continues during the first 23 postnatal weeks [17]. The dose used for enalapril was similar to the dose used by Stevenson et al. [33] and considerably lower than the one used at neonatal age by other authors, usually $10 \mathrm{mg} / \mathrm{kg} /$ day and 30 $\mathrm{mg} / \mathrm{kg} /$ day [20, 34].
Enalapril treatment did not modify the serum ACE activity of pregnant rats in agreement with previous data which suggest that pregnant rats have a capacity to oppose to changes in Ang II level [35]. However, a significant decrease in ACE activity was observed in P0 animals, similarly to data observed in a previous study by using captopril [19]. The lack of effect of enalapril-treatment in the mothers suggest that the observed ACE activity in pups was not due to a decreased in maternal Ang II levels, but rather confirms the direct effect of transplacental transfer of enalapril as reported earlier $[11,15,16,19]$. Since treatment was stopped after birth, no changes in serum ACE activity were observed at later ages, as expected.

The existence of an early pulmonary RAS and high level of pulmonary ACE [1,9,24,32], prompted us to investigate the expression of local RAS components. As reported before in animals treated with captopril, sACE expression level increased in developing lungs with age in both groups, control and enalapril-treated. Our present observations agree with previous reports about an increase in ACE expression during lung development [1, 32]. Previous reports suggest that ACE inhibition results in increased levels of bradykinin and/or prostaglandins [10]. Thus, a compensatory effect of both systems can prevent larger damage in the developing lung.

$\mathrm{AT}_{1}$ expression in rat lungs begins at $\mathrm{G} 15$ and continues to adulthood [32]. Thus, we explored the expression and protein level of $\mathrm{AT}_{1}$ receptors at the different postnatal ages. mRNA for $\mathrm{AT}_{1}$ receptor was high and maintained in control lungs as well as in those exposed to enalapril during late pregnancy. However, protein level of $\mathrm{AT}_{1}$ receptor was higher in P0 pups and drops after that, for either he control or treated groups. $\mathrm{AT}_{1}$ receptors localized in alveolar cells, vascular endothelium and bronchiole epithelial cells in normal developing lungs, as reported in previous studies [36]. Lassegue et al. (1995) described that Ang II down-regulates the expression of $\mathrm{AT}_{1}$ receptor in vascular smooth muscle by transcriptional and post-transcriptional mechanisms [37]. However, in our experimental model no changes were observed following ACE inhibition. On the other hand, $\mathrm{AT}_{2}$ receptor expression was not detectable in control and enalapril treated animals at the different ages studied in agreement with previous reports [36].

During rodent postnatal lung alveolarization, secondary crests develop and extend to make new secondary septa, accompanied by decreased mean alveolar size [17,21,22]. Treatment during late pregnancy with enalapril evidenced a histomorphological alteration in P0 animals, which 
showed fewer alveolar septa and larger terminal air sacs. The histopathological effect observed was comparable to the one observed following postnatal ACE inhibition in rats at a higher dose [20]. Temporal differences were observed between captopril and enalapril treatment, since changes on alveolar histomorphology appeared later in animals treated with captopril. Enalapril treatment modifies the pulmonary saccular morphology but it seems not to affect the process of secondary septa formation. This observation may account for a soon recovery at later stages.

Since lung development is mainly postnatal in rodents, cellular proliferation is expected during the active alveoli septation process. We explored the effect of ACE inhibition in the cellular proliferation process of lung development. Immunohistochemical analyses evidenced high cellular proliferation in developing alveoli at P0 lungs, indicating an active septation process. On the contrary, enalapril-treated pups at birth showed lower PCNA-positive cells which are related to larger airspace quantified by MLI. In agreement with our findings, it has been reported that enalapril treatment during neonatal period decreased the proliferation of myocytes and cardiac interstitial cells [34]. However, increased cellular proliferation was observed at later stages, being maximal at P15 treated animals, presumably as a compensatory mechanism.

Myofibroblasts constitute a subpopulation of $\alpha$-SMApositive rapidly proliferating cells with an apparent role in the septation process. Recently, the role of Ang II as a promoter of human lung fibroblast cell differentiation into myofibroblasts and increased collagen production has been shown [38]. Inmunolocalization of $\alpha$-SMA at P15 in enalapriltreated lungs demonstrated an active elastogenesis at the tips of the developing secondary septa. Myofibroblasts expressing $\alpha$-SMA are associated with regions and periods of development and remodelling [39, 40] as well as in injury repair [40]. Thus, $\alpha$-SMA localization in the treated group in addition with an increased expression of PCNA, suggest an essential participation in alveolar secondary septation process during lung maturation. These observations suggest an impaired cellular proliferation at the saccular stage in lung development caused by ACE inhibition during late pregnancy. These data indicated that beyond the damage caused by enalapril treatment, the developing lungs retain its ability to recover after treatment stopped.

The histomorphological effects observed in developing lungs from treated animals suggest an arrest in the developing program of the lungs which resembles new pulmonary bronchodysplasia [41]. In our previous data using the same dose of captopril, similar histomorphological effects on developing lungs were observed. However, animals treated with enalapril showed a faster and shorter effect. The difference in the effect might be attributed to the potency of both ACE inhibitors, different degrees of functional inhibition or retentiveness, dissociation rates or binding affinity.

In summary, the use of a low dose of ACE inhibitor allowed us to evaluate the effect of the lack of ACE activity during lung development. Treatments were performed during a time-frame critical for lung alveolarization, leading to remarkable effects at postnatal earliest age. Although other multiple local factors could be involved in the developmental process of the lung, the damage observed following ACE inhibition suggests that RAS components are at least partially involved in lung development process. Additional studies will be required to elucidate the mechanisms responsible in alveolar septation by RAS inhibition.

\section{Acknowledgements}

We wish to thank MR Marini and AL Sacrtascini Ciorciari from the Laboratory of Cito-Histopathology (FCV-UNL) for histopathologic analysis contributions. We also thank to members of the Laboratory of Cellular Biology (FCV-UNL) for their technical support. GM Ciuffo and $\mathrm{HH}$ Ortega are members of the researcher's career of CONICET (Consejo Nacional de Investigaciones Científicas y Tecnológicas). DN Capelari has fellowship from CONICET, Argentina. This work was supported by grants from CONICET, PICT15-32350 (ANPCYT) and UNSL, Argentina.

\section{References}

1. Tufro-McReddie A and Gomez RA. Ontogeny of the reninangiotensin system. Semin Nephrol 1993; 13:519-530.

2. Lasaitiene, D. Chen Y, Adams MA, Friberg P. Further insights into the role of angiotensin II in kidney development. Clin Physiol Funct Imaging 2006;26:197-204

3. Sanchez SI, Seltzer AM, Fuentes LB, Forneris ML, Ciuffo GM. Inhibition of Angiotensin II receptors during pregnancy induces malformations in developing rat kidney. Eur $\mathbf{J}$ Pharmacol 2008;588:114-23.

4. Sanchez SI, Arce ME, Fuentes LB, Ciuffo GM. Prenatal blockade of Ang II receptors affects neonatal rat hindbrain structure and receptor localization. Exp Neurol 2009;220(2):246-54

5. de Gasparo M, Catt KJ, Inagami T, Wright JW, Unger T. International union of pharmacology. XXIII. The angiotensin II receptors. Pharmacol Rev 2000;52:415-72.

6. Corvol P, Williams TA, Soubrier F. Peptidyl dipeptidase A: angiotensin I converting enzyme. Methods Enzymol 1995;248:283-305

7. Tian XL, Paul M. Species-specific splicing and expression of angiotensin converting enzyme. Biochem Pharmacol 2003;66:1037-44. 
8. Wallace KB, Bailie MD, Hook JB. Angiotensin-converting enzyme in developing lung and kidney. Am J Physiol 1978;234:R141-5.

9. Wallace KB, Bailie MD, Hook JB. Development of angiotensin-converting enzyme in fetal rat lungs. Am J Physiol 1979;236:R57-60.

10. Buttar HS. An overview of the influence of ACE inhibitors on fetal-placental circulation and perinatal development. Mol Cell Biochem 1997;176:61-71.

11. Cooper WO. Clinical implications of increased congenital malformations after first trimester exposures to angiotensinconverting enzyme inhibitors. J Cardiovasc Nurs 2008;23:204.

12. Guron G, Molne J, Swerkersson S, Friberg P, Hansson S. A 14-year-old girl with renal abnormalities after brief intrauterine exposure to enalapril during late gestation. Nephrol Dial Transplant 2006;21:522-5.

13. Tabacova S, Little R, Tsong Y, Vega A, Kimmel CA. Adverse pregnancy outcomes associated with maternal enalapril antihypertensive treatment. Pharmacoepidemiol Drug Saf 2003;12:633-46.

14. Pryde PG, Sedman AB, Nugent CE, Barr M, Jr. Angiotensinconverting enzyme inhibitor fetopathy. J Am Soc Nephrol 1993;3:1575-82.

15. Quan A. Fetopathy associated with exposure to angiotensin converting enzyme inhibitors and angiotensin receptor antagonists. Early Hum Dev 2006;82:23-8.

16. Stevenson KM, Gibson KJ, Lumbers ER. Comparison of the transplacental transfer of enalapril, captopril and losartan in sheep. Br J Pharmacol 1995;114:1495-501.

17. Burri PH. Structural aspects of prenatal and postnatal development and growth of the lung. 1997.

18. Pua ZJ, Stonestreet BS, Cullen A, Shahsafaei A, Sadowska GB, Sunday ME. Histochemical analyses of altered fetal lung development following single vs multiple courses of antenatal steroids. J Histochem Cytochem 2005;53:1469-79.

19. Capelari DN, Sánchez SI, Ortega HH, Ciuffo G M, Fuentes LB. Effects of maternal captopril treatment during late pregnancy on neonatal lung development in rats. Reg Pep 2012;177:97-106.

20. Lasaitiene D, Chen Y, Nannmark U, Wollmer P, Friberg P. Neonatal ACE inhibition in rats interferes with lung development. Clin Physiol Funct Imaging 2004;24:65-68.

21. Mund SI, Stampanoni M, Schittny JC. Developmental alveolarization of the mouse lung. Dev Dyn 2008;237:210816.

22. Schittny JC, Mund SI, Stampanoni M. Evidence and structural mechanism for late lung alveolarization. Am J Physiology 2008;294:L246-54.

23. Bernstein KE. Views of the renin-angiotensin system: brilling, mimsy, and slithy tove. Hypertension 2006;47:50914

24. Nogueira-Silva C, Carvalho-Dias E, Piairo P, Nunes S, Baptista MJ, Moura RS, Correia-Pinto J. Local fetal lung renin-angiotensin system as a target to treat congenital diaphragmatic hernia. Mol Med 2011;18(1):231-43.

25. Murray BA, Walsh DJ, FitzGerald RJ. Modification of the furanacryloyl-L phenylalanylglycylglycine assay for determination of angiotensin-I-converting enzyme inhibitory activity. J Biochem Biophys Methods 2004;59:127-37.
26. Manzur MJ, Muñoz R, Lucero AA, Juri Ayub M, Alvarez SE, Ciuffo GM. Production of recombinant enzymes of wide use for research. Electron J Biotechnol 2006.

27. Terada Y, Tomita K, Nonoguchi H, Marumo F. PCR localization of angiotensin II receptor and angiotensinogen mRNAs in rat kidney. Kidney Int 1993;43:1251-9.

28. Ruest LB, Khalyfa A, Wang E. Development-dependent disappearance of caspase-3 in skeletal muscle is posttranscriptionally regulated. J Cell Biochem 2002;86:21-8.

29. Adamson IY, King GM. Sex differences in development of fetal rat lung. II.Quantitative morphology of epithelialmesenchymal interactions. Lab Invest 1984;50:461-8.

30. Ortega HH, Salvetti NR, Padmanabhan V. Developmental programming: prenatal androgen excess disrupts ovarian steroid receptor balance. Reproduction 2009;137:865-77.

31. Yamada M, Kurihara H, Kinoshita K, Sakai T. Temporal expression of alpha smooth muscle actin and drebrin in septa interstitial cells during alveolar maturation. J Histochem Cytochem 2005;53:735-44.

32. Morrell NW, Grieshaber SS, Danilov SM, Majack RA, Stenmark KR. Developmental regulation of angiotensin converting enzyme and angiotensin type 1 receptor in the rat pulmonary circulation. Am J Respir Cell Mol Biol 1996;14:526-37.

33. Stevenson KM, Gibson KJ, Lumbers ER. Comparison of the transplacental transfer of enalapril, captopril and losartan in sheep. Br J Pharmacol 1995;114:1495-501.

34. Choi JH, Yoo KH, Cheon HW, Kim KB, Hong YS, Lee JW, Kim SK, Kim CH. Angiotensin converting enzyme inhibition decreases cell turnover in the neonatal rat heart. Pediatr Res 2002:52:325-32.

35. Takeda-Matsubara Y, Iwai M, Cui TX, Shiuchi T, Liu HW, Okumura M, Ito M, Horiuchi M. Roles of angiotensin type and 2 receptors in pregnancy associated blood pressure change. American journal of hypertension 2004;17:684-9.

36. Shanmugam S, Corvol P, Gasc JM. Angiotensin II type 2 receptor mRNA expression in the developing cardiopulmonary system of the rat. Hypertension 1996;28:91

37. Lassegue B, Alexander RW, Nickenig G, Clark M, Murphy TJ, Griendling KK. Angiotensin II down-regulates the vascular smooth muscle AT1 receptor by transcriptional and post-transcriptional mechanisms: evidence for homologous and heterologous regulation. Mol Pharmacol 1995;48:601609.

38. Long X, Xiong SD, Xiong WN, Xu YJ, Zhang ZX, Cao Y, Chen $\mathrm{J}, \mathrm{Xu} \mathrm{XH}$. Losartan inhibited angiotensin induced human lung fibroblast transformation and collagen synthesis. Zhonghua Jie He He Hu Xi Za Zhi 2007;30(4):273-8.

39. Mitchell JJ, Reynolds SE, Leslie KO, Low RB, WoodcockMitchell J. Smooth muscle cell markers in developing rat lung. Am J Respir Cell Mol Biol 1990;3:515-23.

40. Rishikof DC, Lucey EC, Kuang PP, Snider GL, Goldstein $\mathrm{RH}$. Induction of the myofibroblast phenotype following elastolytic injury to mouse lung. Histochem Cell Biol 2006;125:527-34.

41. Bourbon JR, Boucherat O, Boczkowski J, Crestani B, Delacourt C. Bronchopulmonary dysplasia and emphysema: in search of common therapeutic targets. Trends Mol Med 2009; 15:169-79. 
Table 1. Primers and PCR thermocycling parameters

\begin{tabular}{|c|c|c|c|}
\hline Primer & Sequence & PCR conditions & $\begin{array}{l}\text { Size } \\
\text { (bp) }\end{array}$ \\
\hline \multirow[t]{2}{*}{ sACE } & F: 5`- TTCGTGCTACAGTTCCAG-3` & \multirow{2}{*}{$\begin{array}{l}32 \text { cycles: } 95^{\circ} \mathrm{C}, 45 \mathrm{~s} ; 52^{\circ} \mathrm{C}, 1 \mathrm{~min} \text {; } \\
72^{\circ} \mathrm{C}, 1 \mathrm{~min} . \text { Final extension: } \\
72^{\circ} \mathrm{C}, 7 \mathrm{~min} .\end{array}$} & \multirow[t]{2}{*}{569} \\
\hline & R: 5 ` - CTTCTTTATGATCCGCTT-3` & & \\
\hline \multirow[t]{2}{*}{ GAPDH } & F: 5` TCCCTCAAGATTGTCAGCAA-3` & \multirow{2}{*}{$\begin{array}{l}32 \text { cycles: } 95^{\circ} \mathrm{C}, 45 \mathrm{~s} ; 52^{\circ} \mathrm{C}, 1 \mathrm{~min} \text {; } \\
72^{\circ} \mathrm{C}, 1 \mathrm{~min} \text {. Final extension: } \\
72^{\circ} \mathrm{C}, 7 \mathrm{~min} .\end{array}$} & \multirow[t]{2}{*}{309} \\
\hline & R: 5`- AGATCCACAACGGATACATT-3` & & \\
\hline \multirow{2}{*}{$\begin{array}{c}\mathrm{AT}_{1} \\
\text { receptor }\end{array}$} & F: 5`- GTCATGATCCCTACCCTCTACAGC-3` & \multirow{2}{*}{$\begin{array}{l}32 \text { cycles: } 95^{\circ} \mathrm{C}, 1 \mathrm{~min} ; 64^{\circ} \mathrm{C}, 1 \\
\min ; 72^{\circ} \mathrm{C}, 1 \mathrm{~min} \text {. Final extension: } \\
72^{\circ} \mathrm{C}, 7 \mathrm{~min} .\end{array}$} & \multirow[t]{2}{*}{823} \\
\hline & R: 5`- CGTAGAACAGAGGGTTCAGGCAG-3` & & \\
\hline
\end{tabular}

sACE: somatic angiotensin converting enzyme; GAPDH: glyceraldehyde 3-phosphate dehydrogenase; F: forward primer; R: reverse primer.

Table 2. Body and lung weights from control and enalapril-treated rats at the different postnatal stages.

\begin{tabular}{|c|c|c|c|c|}
\hline & 0 day & $\mathbf{8}$ days & 15 days & 30 days \\
\hline Body weight (g) & & & & \\
\hline Control & $6.07 \pm 0.25$ & $12.54 \pm 1.29$ & $27.12 \pm 1.90$ & $78.61 \pm 9.54$ \\
\hline Enalapril & $5.84 \pm 0.26$ & $10.89 \pm 1.92$ & $26.25 \pm 1.05$ & $61.72 \pm 16.72$ \\
\hline Lung weight (g) & & & & \\
\hline Control & $0.14 \pm 0.03$ & $0.34 \pm 0.03$ & $0.55 \pm 0.03$ & $0.75 \pm 0.05$ \\
\hline Enalapril & $0.14 \pm 0.03$ & $0.35 \pm 0.06$ & $0.54 \pm 0.03$ & $0.68 \pm 0.07$ \\
\hline Lung/body weight & & & & \\
\hline Control & 0.023 & 0.026 & 0.020 & 0.009 \\
\hline Enalapril & 0.024 & 0.032 & 0.020 & 0,010 \\
\hline
\end{tabular}

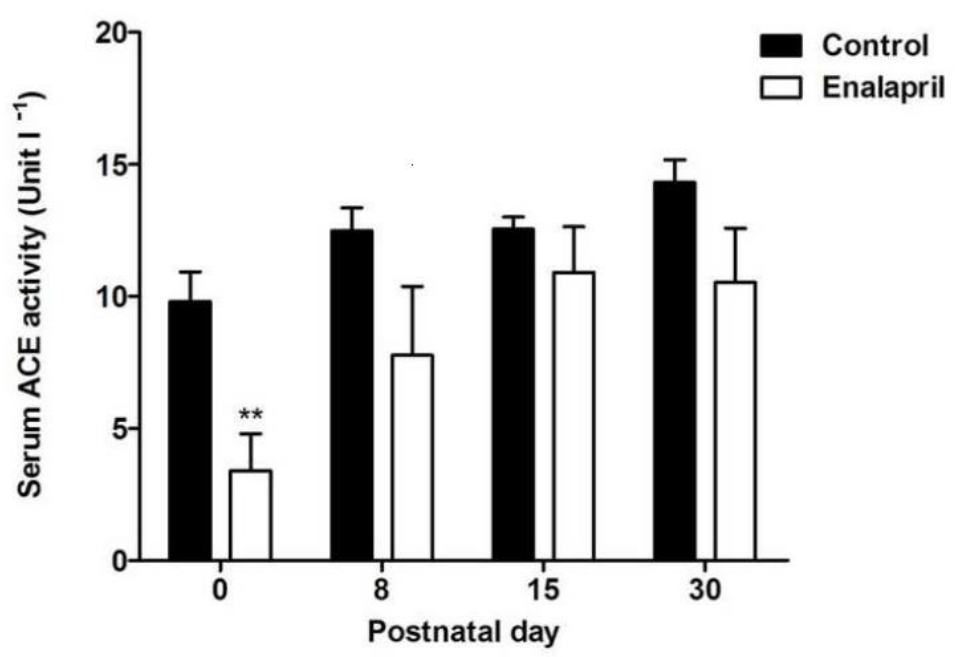

Fig. 1. Serum ACE activity in control and enalapril-treated rats. Serum ACE activity was evaluated by FAPGG hydrolysis at different postnatal ages. Data are mean \pm SEM from three independent treatments of the pregnant mothers, 3 animals per treatment $(\mathrm{n}=9)$. ACE activity decreased significantly in neonatal (P0) enalapril-treated rats $(* * P<0.01)$. No significant differences were detected in enalapril treated group at postnatal days 8,15 and 30 respects to control group. 
A
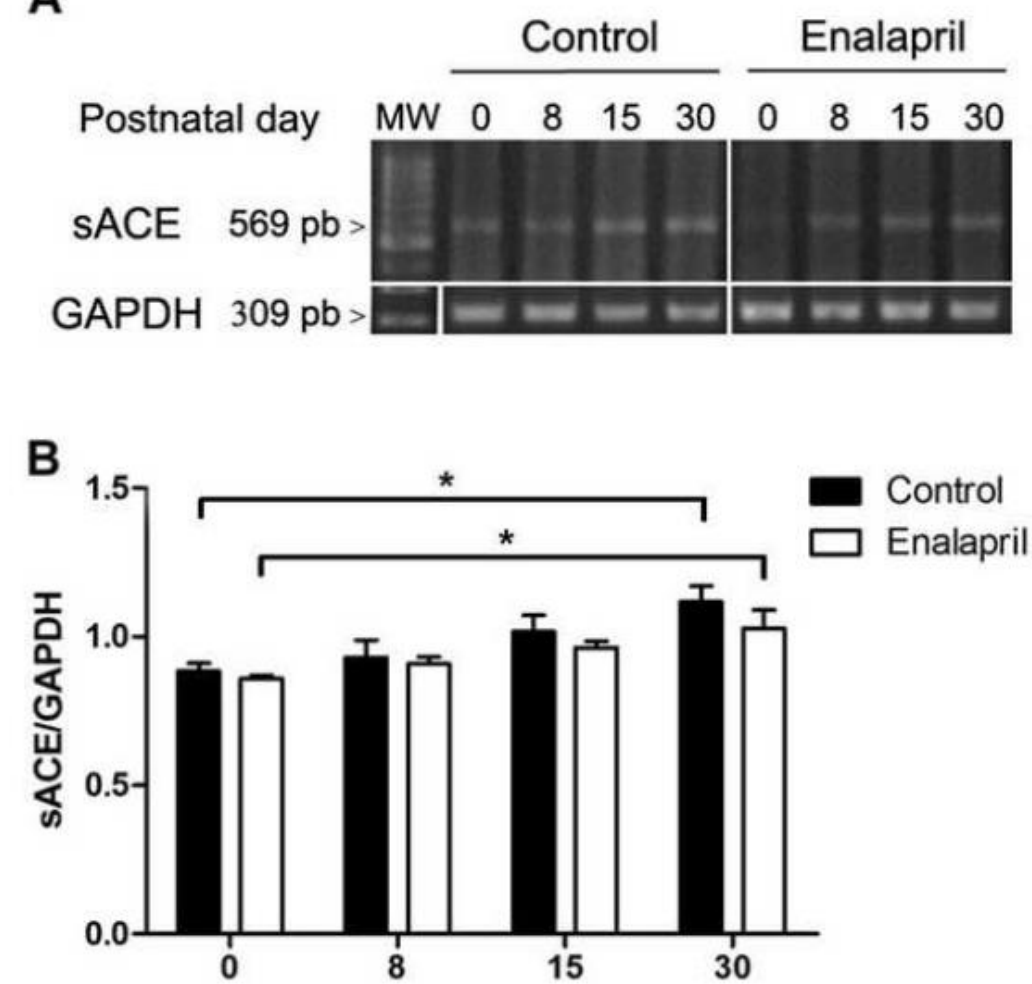

Fig. 2. Somatic ACE (sACE) expression at different postnatal ages in control and enalapril-treated rat lungs. A. Representative gel from the RT-PCR products of sACE and GAPDH for control and treated groups. MW: molecular weight marker. B. Densitometric data normalized against GAPDH, shown as means \pm SEM of six independent experiments. sACE expression evidenced an increase from P0 to P30, in control animals as well as in enalapriltreated group $(* P<0.05)$.

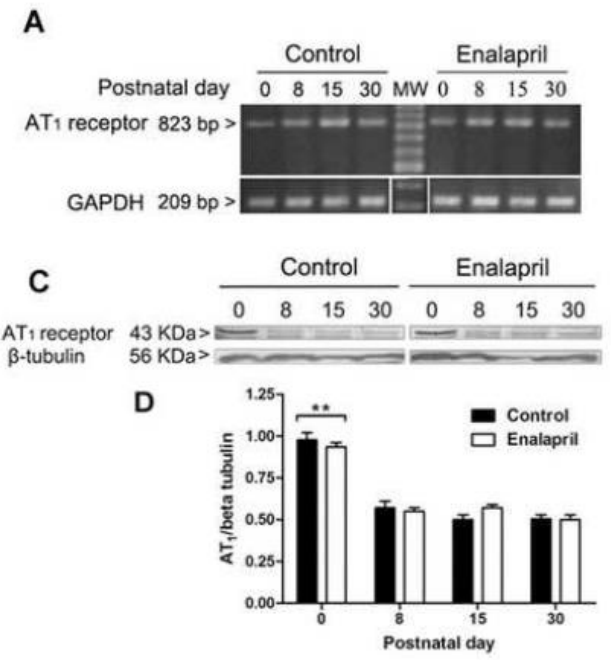

B
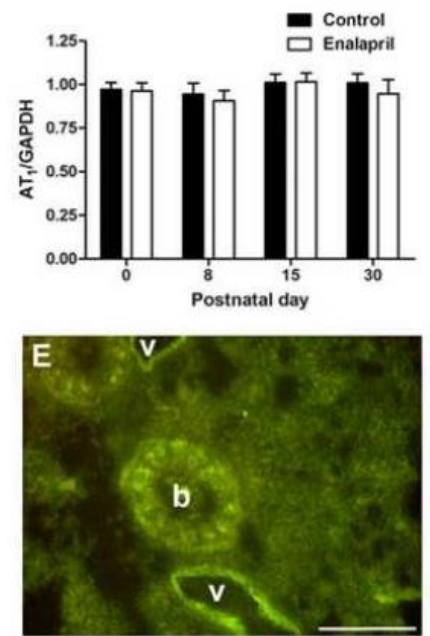

Fig. 3. $A T_{1}$ receptor expression of control and enalapril-treated groups in developing lungs. A. Representative gel from the RT-PCR performed to evaluate mRNA expression of $\mathrm{AT}_{1}$ receptor and normalized against GAPDH for different stages and treatments. MW: molecular weight marker. B. Densitometric data are shown as means \pm SEM of six independent experiments. C. Western blot analysis showing $\mathrm{AT}_{1}$ receptor protein expression in lung development; $\beta$ tubulin is used as loading control. D. Data represent mean \pm SEM of four independent experiments Western blot analyses normalized to $\beta$ tubulin. E. Immunofluorescence localization of $\mathrm{AT}_{1}$ receptor in lung section from control group at $\mathrm{P} 8$. $\mathrm{AT}_{1}$ receptor localized at alveolar cells, endothelial cells (arrowhead) and bronchial epithelial cells (arrows). B: bronchiole, V: vessel. Bar=50 $\mu \mathrm{m}$. 


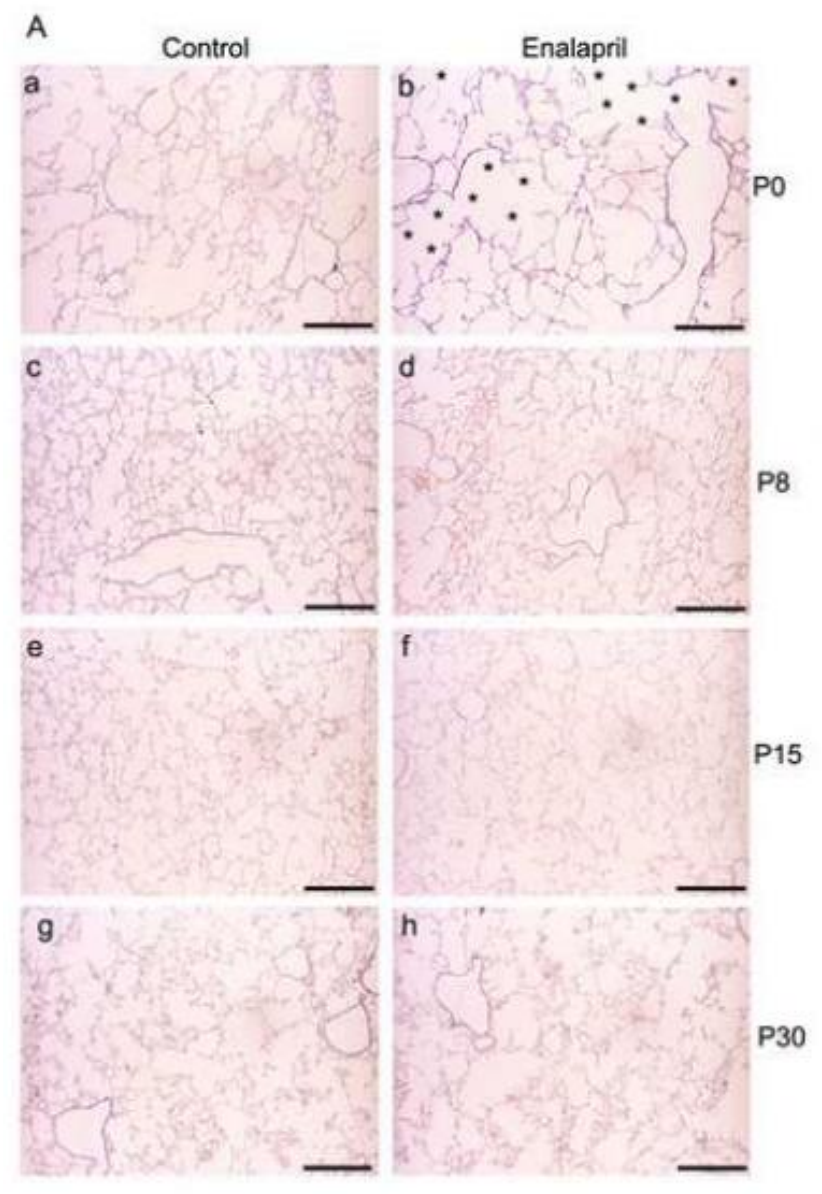

B

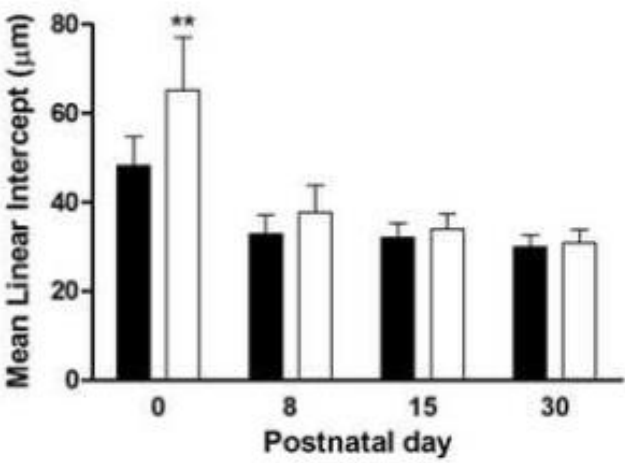

15

30

Fig. 4. Airway morphology and morphometric measurements of lung sections in postnatal development. A. Representative photomicrograph of control (a, c, e, g) and enalapril-treated(b, d, f, h) groups at P0, P8, P15 and P30. Larger airway spaces can be observed in enalapril-treated lungs at P0 (b, asterisks). Scale bars=100 $\mu \mathrm{m}$. B. Morphometric quantification of alveolar sizes by mean linear intercept (MLI) from control and enalapril-treated groups during development. Enalapril-treated animals showed significative differences at $\mathrm{P} 0(* * \mathrm{P}<0.01)$ compared with control. No significant differences were observed at P8, P15 and P30 of enalapril-treated animals in comparison with vehicle-treated group. Data are means \pm SEM, from 6 independent treatments. 

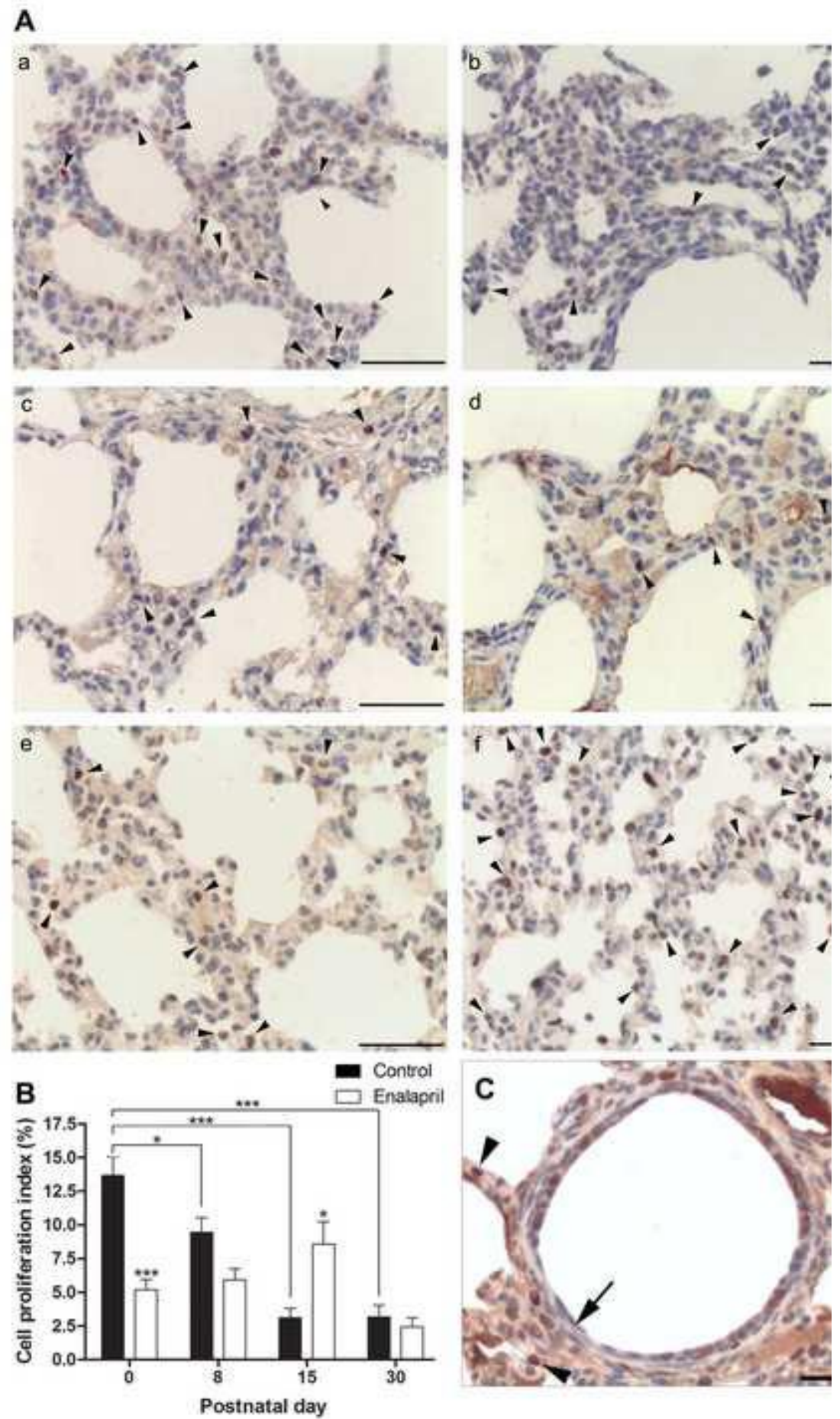

Fig. 5. Immunolocalization of proliferating cell nuclear antigen (PCNA) in postnatal lung development. A. Immunohistochemistry of PCNA (brown) counterstained with hematoxylin. Positive staining (arrowheads) for proliferating cells was observed in the alveolar septa in control lungs at P0, P8 and P15 (a, c, e) and enalapril-treated (b, d, f). Scale bars $=20 \mu \mathrm{m}$. B. Positive cells were quantified and data expressed as a percentage of total pneumocytes. Cell proliferation in control animals decreased significantly during the studied postnatal period $(* * * P<0.001)$. PCNA-positive cells quantified in epithelial airways in enalapril-treated lungs were lower at P0 than the control $(* * * P<0.001)$ and was increasing significantly at P15 $(* P<0.05)$. Data are means \pm SEM, from four independent treatments. C. Co-immunolocalization of PCNA and cytokeratin counterstained with hematoxylin at P15. Positive staining (arrowheads) for PCNA (brown) was observed in the alveolar septa in enalapril-treated lung. Co-staining with anticytokeratin is shown in pulmonary alveolar epithelium (red). Scale bars=20. 

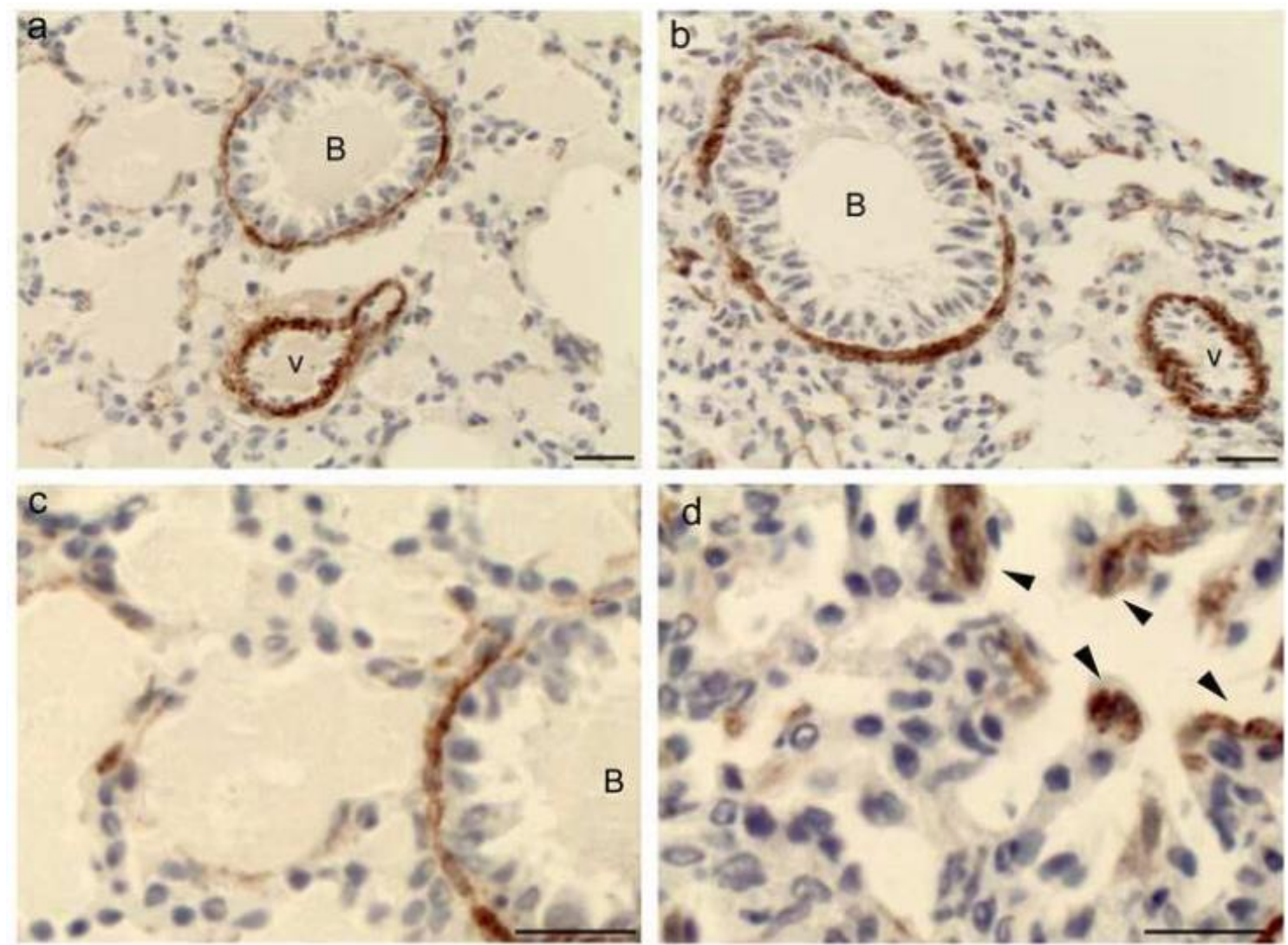

Fig. 6. Immunolocalization of $\alpha$-smooth muscle actin ( $\alpha$-SMA) at P15 lungs. $\alpha$-SMA was restricted to the cytoplasm of bronchiolar myocytes and vessel walls (arrows) from control (a, c). Enalapril-treated lungs (b,d), $\alpha$ SMA recognized myofibroblasts at the tips of developing septa (arrowhead), smooth muscle cells at bronchiolar (B) and vessel (V) walls. Bars $=20 \mu \mathrm{m}$. 